\title{
Assessment of historic concrete structures
}

\author{
R. Brueckner \& P. Lambert \\ Mott MacDonald, Materials and Corrosion Engineering, UK
}

\begin{abstract}
Concrete has been used as a construction material for several thousand years. The concrete as known today was only developed around 150 years ago after the technology was all but lost for a millennium after the fall of the Roman Empire. Historic concrete structures therefore generally only date back second half of the $18^{\text {th }}$ century. Structures that date further back are considered to be ancient concrete. The structures that require attention and therefore an assessment generally belong to the more recent period.

Concrete can be a very durable construction material and it was initially thought that it could essentially last forever, however, this has subsequently been proven to be wrong. Concrete can deteriorate as a result of structural inadequacies and due to chemical interactions between the concrete constituents, external aggressants and the embedded steel reinforcement. The deterioration patterns vary from purely cosmetic cracking, cracks affecting the structural integrity, ineffective protection against reinforcement corrosion and loss of steel cross sectional area.

This paper provides an overview of many of the different types of deterioration that can be encountered in historic concrete structures and how the cause and severity can be assessed using different investigative techniques. Keywords: concrete, corrosion, deterioration, assessment, investigation.
\end{abstract}

\section{Introduction}

The history of concrete as a building material can be dated back to at least 5600 BC at Lepenski Vir, Serbia on the Balkan Peninsula. More widespread and considered use of ancient concrete is recorded from 3000 BC onwards in Egypt, Assyria, Babylon and China [1]. Probably most famous concrete structure from ancient times is the Pantheon in Rome which was built around 120 AD. During the Roman Empire concrete had undergone various significant developments 
with the discovery of the pozzolanic properties of volcanic ash from Pozzouli, a small town close to Vesuvius. The addition of lime to the ash initiated a complex hydration reaction to form calcium-silicate-hydrates which are the principal strength giving hydrates in concrete.

After the fall of the Roman Empire the formulation of such advanced concretes was largely lost for more than a millennium until the $18^{\text {th }}$ century when John Smeaton's development of a hydraulic cement for use in the construction of the Eddystone Lighthouse off the south west coast of England. The rise of the modern Western civilizations, beginning with the great migrations to North America and the subsequent industrialisation, required the development of stronger, durable and more readily available building materials. The existing traditional brick, stone and timber construction methods were proving insufficient to meet the demand for fast, durable construction.

The completion of the Bridgewater Canal in the North West of England in 1761 and its subsequent extraordinary success led to widespread improvements in the transport system of Britain. In the British colonies of North America the challenges imposed during the planning and construction of the $584 \mathrm{~km}$ Erie Canal required the development of a plentiful and rapidly constructed watertight material. Modern concrete was born when Joseph Aspdin, a Leeds bricklayer and mason, patented Portland cement in 1824. He had created the first massproduced and widely accepted artificial cement by burning ground limestone and clay together. The basic recipe of Portland cement has remained largely unchanged until the present day and forms the basis of most concretes and hydraulic mortars.

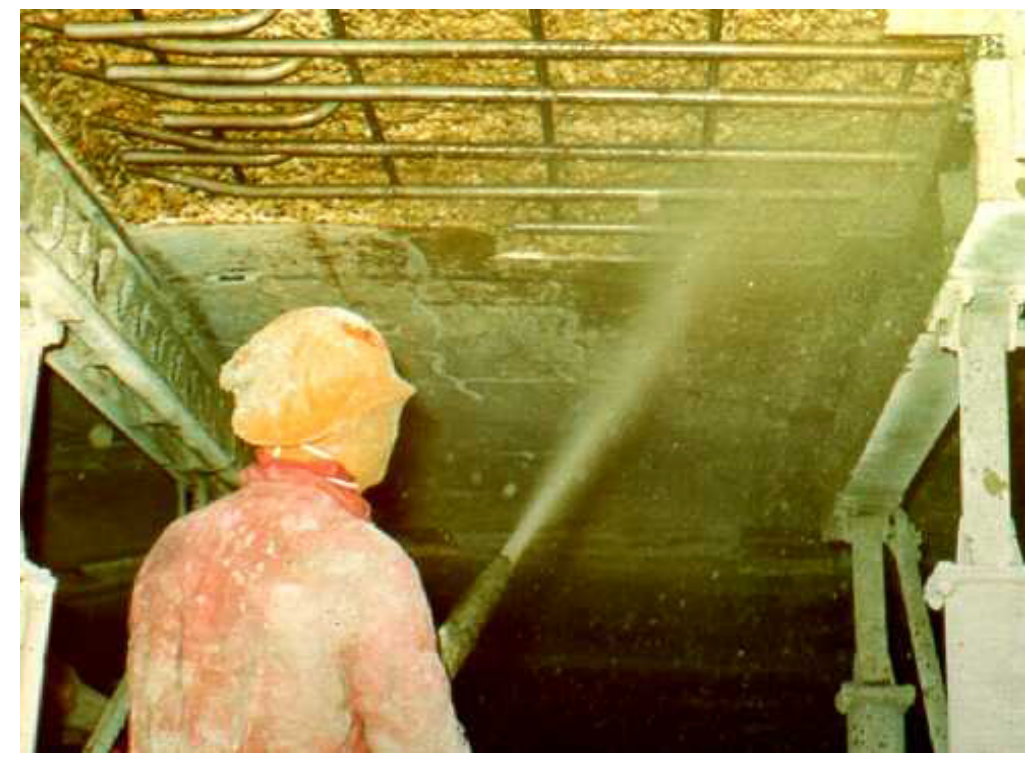

Figure 1: Repair to the 1930s' reinforced concrete. 
Reinforced concrete, or ferroconcrete, containing embedded steel reinforcement appears to have been invented by Joseph Monier in 1849 but was not patented until 1867 [2]. Monier was a gardener from Paris who built garden pots of concrete with an iron mesh. Later he promoted the use of reinforced concrete for pipes, floors, arches and bridges.

Other types of cement were developed at the beginning of the $20^{\text {th }}$ century which have been used in the construction of concrete structures, usually with only limited success. This may have been due to the dominance and reliability of Portland cement concretes and the problems in their use that were often encountered.

Historic concrete structures that are nowadays encountered during restoration works have mainly been constructed during the end of the $19^{\text {th }}$ and beginning of the $20^{\text {th }}$ century. Construction codes were not established until the early 1900 and many innovations came in and out of standards as first their benefits were recognised but subsequently their limitations were identified decades later.

When such old structures are required to be assessed with regard to the structural integrity and durability for restoration or alteration works it is important to know what to look for and how to identify potential risks.

\section{Causes of concrete deterioration}

\subsection{Corrosion}

Corrosion of reinforcement embedded in concrete is mostly commonly the result of either or both carbonation of the cover concrete or penetration of chlorides. Ferrous material, such as wrought iron or steel are normally protected in an alkaline environment by a stable oxide film formed on the metal surface. The $\mathrm{pH}$ of concrete is above 12.5 and can reach up to around 14, thus providing such

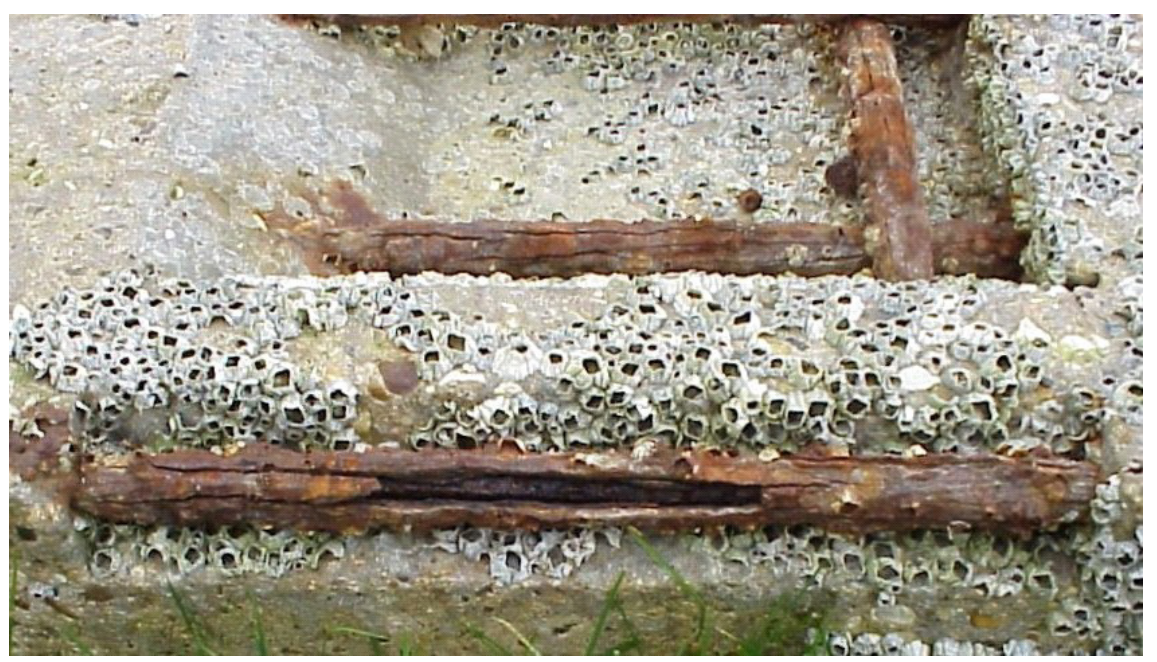

Figure 2: Corrosion of reinforcement. 
protection. However, this protective alkalinity can be lost through the effect of carbonation which reduces the alkalinity to below $\mathrm{pH}$ 9. Carbonation is a natural process when carbon dioxide from the air reacts with calcium hydroxide and other alkalis in the concrete to form calcium carbonates while reducing the alkalinity. The protective oxide film becomes unstable in carbonated concrete and may initiate corrosion in the presence of moisture and oxygen (Figure 2).

Deterioration may also occur due to chloride induced corrosion. Chloride can penetrate the concrete and if the chloride content exceeds a critical threshold on the surface of the reinforcement corrosion may initiate, despite a highly alkaline environment. Nowadays the most common cause is chloride externally deriving from de-icing salts spread on roads and walkways. However, it was common practice to use calcium chloride as an accelerating admixture in concrete until 1977 and the historic use of marine dredged aggregates often means older concretes had significant chloride levels from new.

Calcium chloride is an accelerating admixture that is added to concrete either to increase the rate of early strength development or reduce the setting time, particularly in cold weather. Such positive effects of calcium chloride on fresh concrete have been known of since 1873 [3] with the first patent from 1885 [4].

Calcium chloride as an accelerator and cold weather admixture has been widely used in construction but because of its negative effects on the durability of reinforced concrete has been widely banned from use and replaced by less aggressive modern alternatives.

The corrosion of steel reinforcement was not properly considered until 1977 when calcium chloride was effectively banned in the UK. The Code of Practice CP110 stated in its revised version from 1977 that: "Experience shows that corrosion of prestressing tendons, reinforcement and embedded metal usually results from the combination of factors including excess addition of calcium chloride ... departure from specified mix proportions, poor compaction, inadequate cover and poor detail design.” BS 8110:1985 clearly states that "Calcium chloride and chloride-based admixtures should never be added in reinforced concrete, prestressed concrete and concrete containing embedded metal."

\subsection{Cracking}

There are many different types of cracks that can occur in concrete. The consequence of these can range from purely aesthetic to structurally significant, and care should be taken when assessing them. It should always be borne in mind that concrete will always crack as a result of shrinkage during curing and drying, but that these cracks should be fine and well distributed and not normally be structurally significant (Figure 3). As concrete has a low tensile strength, cracks may also be a result of the manner in which it performs structurally.

Cracking in the early life of a structure may be attributed to plastic settlement, plastic shrinkage and early age thermal cracking but historic concrete structures are more likely to exhibit long-term drying shrinkage, structurally related cracking, cracking as a result of carbonation, cracking due to corrosion, sulphate attack or alkali-aggregate reactions. 


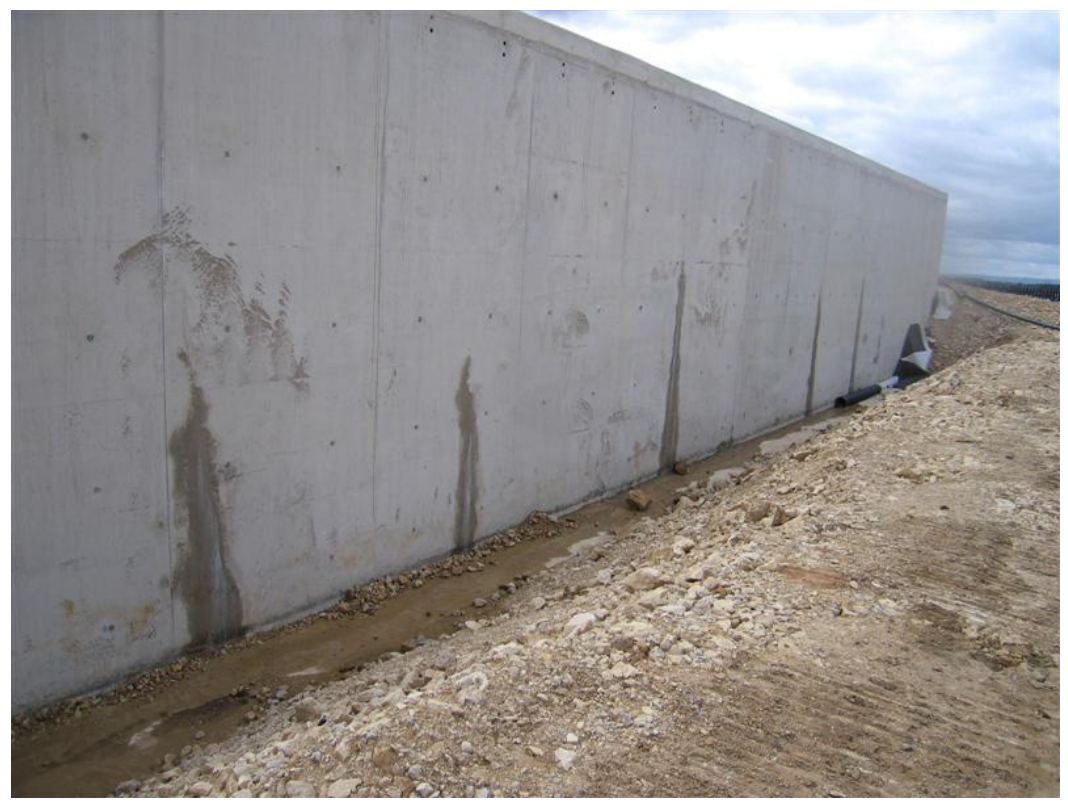

Figure 3: $\quad$ Shrinkage cracks.

\subsection{Cement types}

The most common and highly successful cement used in the construction of concrete structures remains Portland cement; however, several other types and variations have been patented. Ordinary Portland cement is not suitable for all environmental conditions such as aggressive soils and solutions and is now commonly blended with slag and pozzolanic materials to improve its durability. To resist aggressive environments sulphate-resisting cements, such as supersulphated cement and high-alumina cement (HAC) have been developed both subsequently proved to have problems with respect to durability and repair.

Structures consisting of super-sulphated cement concrete can provide a significant challenge to the achievement of long lasting repairs. Due to the high sulphate content it is not possible to successfully repair with Portland cement based materials as the risk of sulphate attack at the interface between the original substrate and repair mortar could cause secondary degradation.

High-alumina cement is a fast setting cement with a high resistance to sulphate attack, however, it undergoes a potentially disastrous conversion process in warm and humid environments. That involves a change in the mineralogy of the cement, which becomes increasingly porous and friable with age and also loses alkalinity. The porosity of the paste increases and therefore the strength of the hydrated cement paste significantly reduces. Also, the increased porosity means the concrete is more susceptible to other forms of attack such as alkali attack, sulphate attack, or carbonation which may result in reinforcement corrosion. Structures, which were constructed between the 1920s and the mid 
1970s may contain HAC elements, this can include schools, swimming pools and bridges. The type of cement should be identified before any restoration takes place and where appropriate strengthened or replaced.

Asbestos cement was developed in the United States in the early 1900s to form a more durable and fire resistant material which was also easier to process, form and install [5]. At the time it was considered to have many economic benefits, however, over time the terrible health risks associated with the use of asbestos fibres became widely recognised. Asbestos cement used to be a very variable and much used material in the construction industry until the 1960s in Mainland Europe when it was phased out of production; however, it was not until 1998 that it was also finally banned from use as preformed sheet materials for use in construction works in the UK.

\subsection{Alkali aggregate reaction}

Alkali aggregate reaction (AAR) and the more specific variant 'alkali silica reaction' was first reported in the United States by T.A. Stanton in 1940 [6]. The reaction between alkali and aggregate as the cause of concrete degradation has been investigated since the early 1920s due to the occurrence of AAR in a dam in California. Europe and the United Kingdom generally assumed that AAR was a degradation process which only occurred in North America until first cases were discovered in the early 1970s. To date evidence of AAR deterioration has been found throughout the world, as having often been misdiagnosed in the past as some other form of cracking.

AAR is a chemical reaction between various forms of aggregate, commonly silica, and the alkali hydroxides in the cement paste in presence of moisture to form a more voluminous gel. The expansive forces exceed the tensile strength of the concrete which causes cracking. It affects the appearance and serviceability of a structure but it generally does not affect the structural integrity. However, AAR is often considered to be a predecessor of other deterioration mechanisms such as corrosion and sulphate attack.

\subsection{Sulphate attack}

The effect of sulphates on concrete has been known since 1877 and damage was primarily discovered on structures in Europe. It was not until the early 1900s than sulphate attack was also identified as a cause of deterioration in North America. The attack comprises the reaction between sulphates from internal or external sources with the calcium aluminate hydrates in the presence of moisture. Michaelis called the salt formed 'cement bacillus' but it is now more commonly known as 'ettringite' [7], and is the main reaction product formed by the expanding form of sulphate attack. Sulphates can also attack concrete by leaching of the calcium containing phases or can form a mushy paste (thaumasite) by reacting with the calcium silicate hydrates, the strength giving agent, in the cement paste.

Sulphate attack of historic concrete structures may occur late in life due to exposure to an external sulphate source. Attack due to internal sulphate sources, 
notably delayed ettringite formation (DEF) is more likely during the early stages of a structure's life.

\subsection{Historic reinforcing bars}

The now common deformed high yield reinforcing bar is a relatively recent introduction. Early reinforced concrete systems used wrought and even occasionally cast iron bars to enhance the performance of the concrete and attempts were often made to improve the bond and anchorage by twisting the bars (Figure 4) or splaying the ends into fishtales as used at Thorverton Bridge (Figure 6).

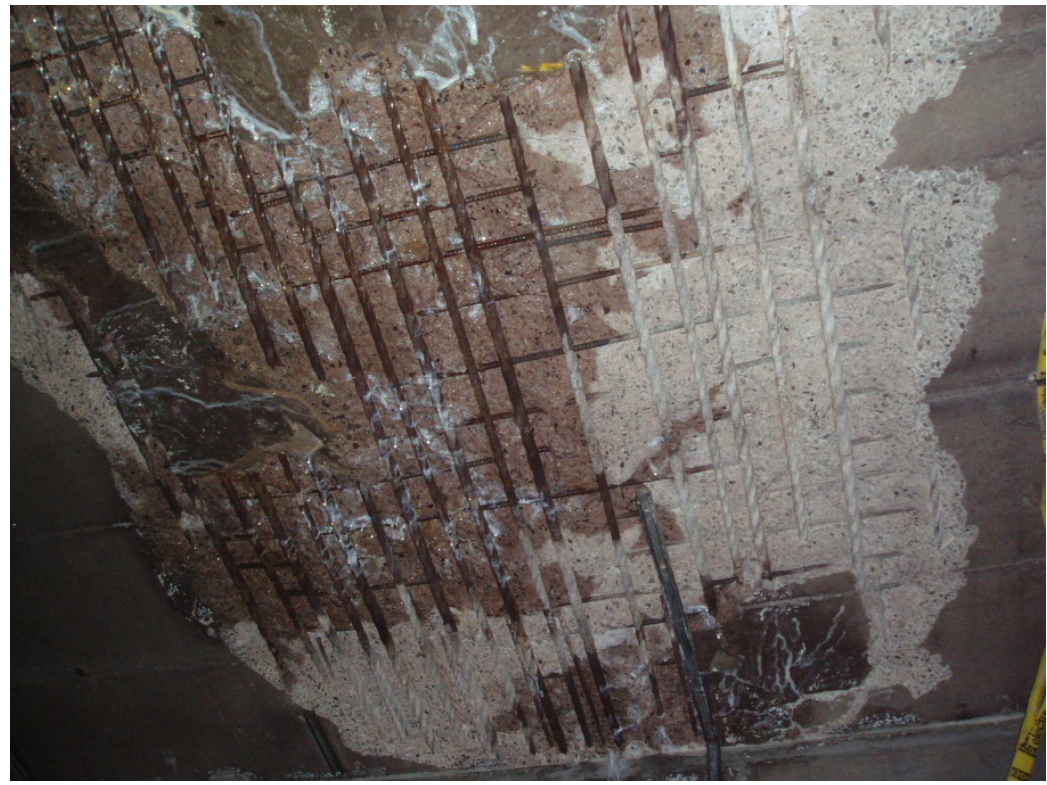

Figure 4: $\quad$ Square twisted reinforcement.

The majority of 'old' reinforced concrete will employ smooth round mild steel reinforcement or welded meshes, the latter still being employed in the construction of floor slabs.

When adding additional reinforcement to areas damaged by corrosion it is preferable to tie rather than tack weld the new reinforcement as the original bars may be higher in carbon than modern materials and difficult to weld successfully. The same is true when establishing electrical continuity, for example, prior to installing a cathodic protection system, with mechanical forms of bonding preferable to welded connections. 


\section{Assessment}

\subsection{Visual inspection}

Structures should firstly be visually inspected to assess the current condition, identify safety related works that may need to be initiated immediately and to develop an investigation strategy. The visual inspection should comprise the recording of any evidence of deterioration e.g. cracking, delamination and efflorescence.

The crack pattern should be assessed as it can provide an indication of the cause of deterioration. Long-term drying shrinkage cracks are typically uniformly spaced across the structure as the concrete tends to shrink in a uniform manner over a significant period of time. Cracks caused by corrosion may occur be associated with areas of delaminated or spalled concrete. Evidence of corrosion products along the cracks may support this diagnosis.

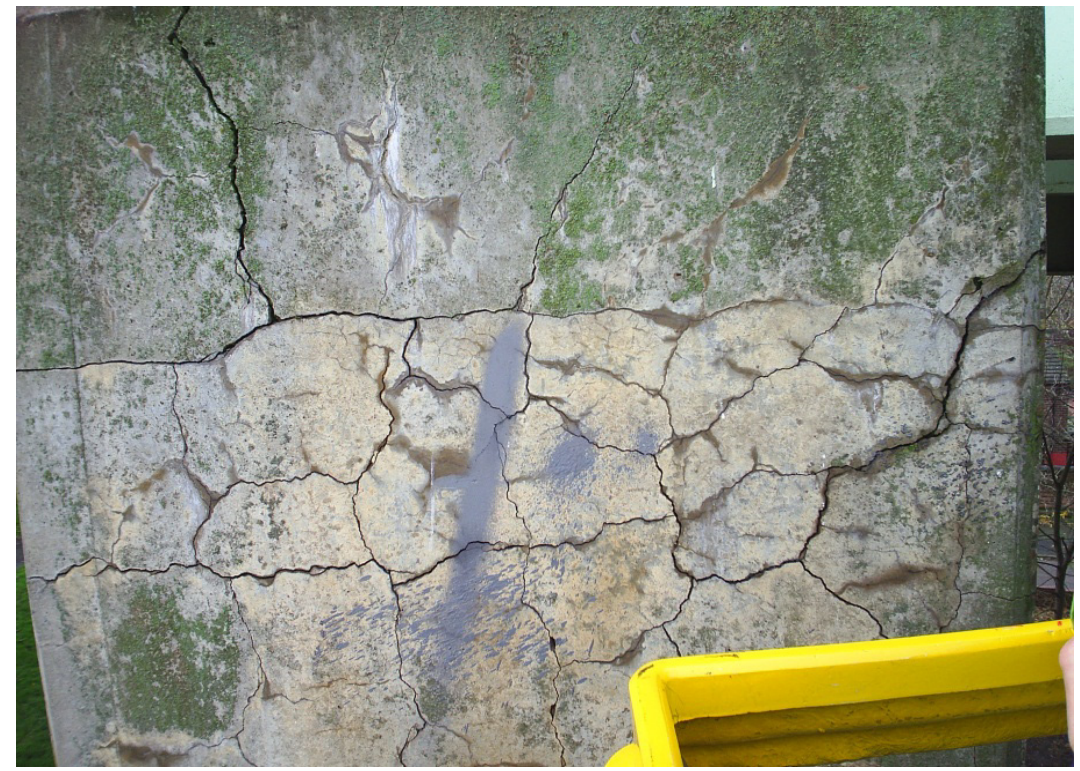

Figure 5: Cracking as a result of alkali aggregate reaction.

Cracks caused by alkali aggregate reaction have a typical appearance of a spider's web with three-way cracks which may be filled with a white or offwhite gel (Figure 5). This gel is the product of the alkali-aggregate reaction, is soluble and therefore may be washed out.

Efflorescence is an indication of moisture movement which could suggest that a leaching process is occurring or that the structure is periodically exposed to moisture and salts. Dissolved salts are transported towards the surface where evaporation causes crystallisation of salts which may lead to damage of the concrete surface. 


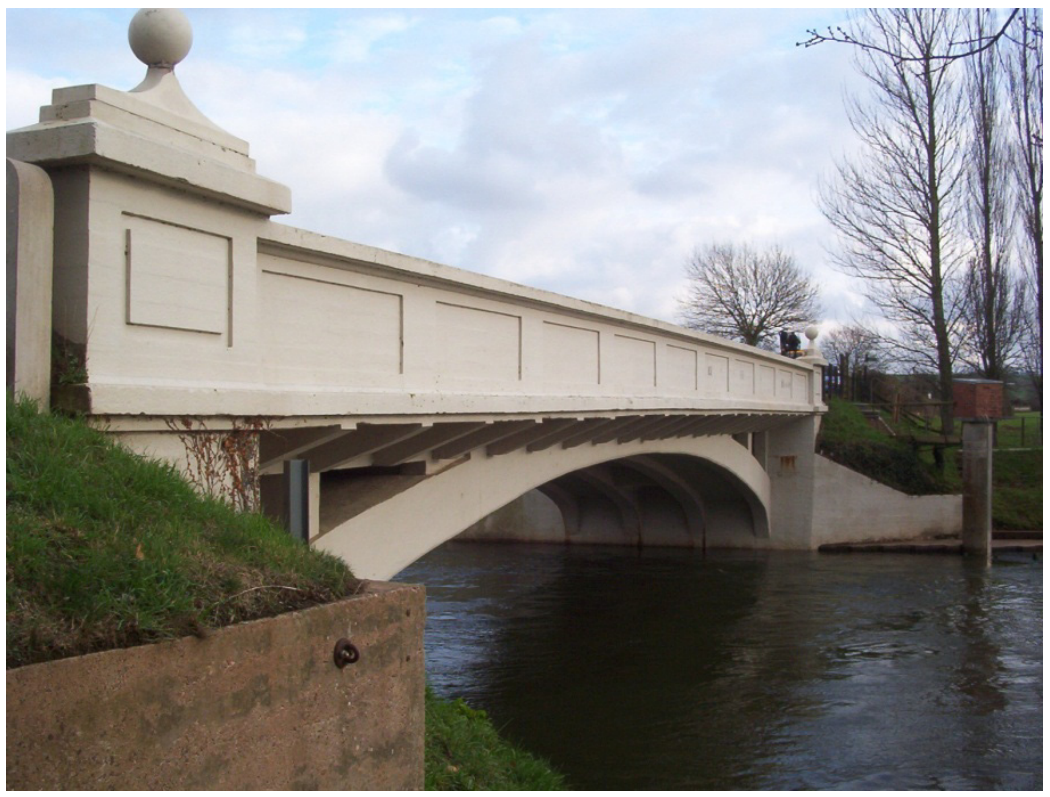

Figure 6: Thorverton Bridge, built 1908, following repair.

\subsection{Compressive strength}

To assess a concrete structure for its integrity it is firstly required to determine the compressive strength of the concrete. The compressive strength can be determined using destructive and non-destructive techniques. The most reliable method is to retrieve core samples and destructively test these for compressive strength. However, historic structures may be subject to restrictions for destructive testing.

The most common non-destructive method is using a Schmidt Hammer (sclerometer) which is a device that strikes a concrete surface with a given energy. The rebound of the hammer is determined by the hardness of the concrete. The values obtained from the Schmidt Hammer can then be converted into compressive strength figures.

The destructive and non-destructive testing methods and their analysis are covered by national standards, for example, BS 6089 and BS EN 13791.

\subsection{Cement type}

The type of cement used in the concrete needs to be determined before any repair works are carried out. The use of a non-compatible repair material may lead to limited life repairs or destructive reactions within the structure. For example, if the original concrete is based on super-sulphated cement and a Portland cement based repair material is used then this may lead to sulphate attack at the repair interface. 
The type of cement can be determined by chemical methods or petrographic analysis. Petrography is a tool which provides a significant amount of data of the concrete (see section 3.5).

\subsection{Corrosion}

Corrosion can be visually identified by the evidence of cover concrete delamination and corrosion products on the reinforcement. The corrosion products are more voluminous than the original steel causing expansion which may lead to delamination of the cover concrete. The tensile strength of the concrete is approximately one tenth of the compressive strength and therefore is not sufficient to withstand the tension forces.

The deterioration pattern of carbonation-induced corrosion is typically uniform corrosion and widespread delamination whereas chloride-induced corrosion may occur in a more localised form. The carbonation process is generally uniform on an element but the rate can be affected by the local environmental conditions. The rate of carbonation increases with decreasing moisture content of the concrete and is zero in saturated, submerged or buried conditions.

Chloride induced corrosion may be visually identified by more localised deterioration where chloride has been able to penetrate the concrete and exceed a critical threshold of $\mathrm{t}$ to initiate corrosion. The chloride threshold value is commonly stated as $0.4 \%$ by weight of cement, although in practice levels of chloride as high as $1 \%$ by weight of cement may be encountered with no apparent corrosion risk. The deterioration pattern depends on the availability of moisture and the extent of exposure to chlorides in the case of externally sources. Admixed chlorides may be present in concrete up to $2.28 \%$ by mass of cement or even higher [8]. Research suggests that approximately 25 to $50 \%$ of total chlorides can be bound in the hydration products [9-11]. The free chloride content, which is responsible for corrosion initiation, may increase over time when the concrete carbonates and bound chlorides are released.

To assess the cause of corrosion or the risk of corrosion initiation on a structure, the concrete should be tested with respect to its chloride content and carbonation depth at representative locations. The chloride content can be determined by obtaining dust samples or retrieving cores. The chloride profile is assessed from the surface inwards at $25 \mathrm{~mm}$ increments having first disguarded the initial $5 \mathrm{~mm}$ which may be contaminated by the local environment, i.e. 5$25 \mathrm{~mm}, 25-50 \mathrm{~mm}$ and $50-75 \mathrm{~mm}$. An increasing or decreasing profile indicates an external chloride source whereas a more even profile of approximately 1$1.5 \%$ by mass of cement indicates an internal source of admixed calcium chloride. It is possible that the chloride content in the immediate surface may be partly depleted due to wash out.

The depth of carbonation should be determined on delaminated samples or cores. Core samples should be split on site to expose a fresh surface and phenolphthalein indicator solution applied to the broken surface. Magenta coloured areas indicate uncarbonated and clear areas carbonated concrete. 
In addition to the determination of the cause of corrosion the concrete, cover depth should be determined to assess the risk of corrosion in to date unaffected elements. This can be carried out using a commercially available covermeter.

\subsection{Petrographic analysis}

Petrography has been used to examine rock samples so as to identify their mineralogical and chemical characteristics since the middle of the $19^{\text {th }}$ century. Towards the end of the $19^{\text {th }}$ century the technique was applied to cementitious materials and nowadays is an important tool to identify the properties of concrete and the cause of any deterioration observed during a visual inspection. It should be seen as one of the tools available as part of the investigation, alongside physical testing, chemical testing and visual inspection [12].

Petrography can be used to obtain information about the quality of the concrete, i.e. the original mix design comprising cement type and content, watercement ratio, degree of compaction and the type and distribution of aggregates. The risk of potential alkali aggregate reaction can be assessed based on the type of aggregates. The depth of carbonation, the extent and progress of AAR and other causes of cement paste deterioration such as sulphate attack can also identified, along with the causes of cracking if due to internal deterioration mechanisms.

Specimens for petrography are generally obtained from cores from which thin sections of approximately $25-30 \mu \mathrm{m}$ thickness are prepared and examined using a polarising microscope.

\section{Summary}

For all its critics, concrete, especially in its steel reinforced form, has proved to be an invaluable and largely durable material for construction. It remains the most used material worldwide but this should not distract from the cultural and aesthetic values of the early examples.

Improved understanding of the mechanisms of degradation and the availability of enhanced methods of investigation allows important examples of historic concrete to be properly assessed and sensitive repair strategies to be developed to ensure they remain safe, serviceable and available for continuing public access and use long into the future.

\section{References}

[1] Schaeffer, R.E., Reinforced Concrete, Preliminary design for Architects and Builders; Handout on Skyscrapers, McGraw-Hill Inc., World Book Encyclopedia, 1992.

[2] Encyclopædia Britannica, www.britannica.com/EBchecked/topic/389450/ Joseph-Monier.

[3] Kuhl, H. and Ullrich, E., Chloride cracking. Zement, 14, pp. 859-861; 880882; 898-901; 917, 1925. 
[4] Millar, W. and Nichols, C.F., Improvements in means of accelerating the setting and hardening of cements. Brit. Patent No. 2, 886, March 4, London, England, 1885.

[5] Hornbostel, C., Construction Materials: Types, Uses and Applications, John Wiley \& Sons, New York, 1978.

[6] Stanton, T. A. In Proceedings of American Society of Civil Engineers 1940, pp. 1781-1811.

[7] Michaelis, W. Tonindustrie-Zeitung 1892, 6, pp. 105-106.

[8] Imperial Chemical Industries Ltd., Calcium chloride - in concrete making. 2nd Edition, Printed by Mears \& Caldwell Ltd. London, 1958.

[9] Richartz, W., Die Bindung von Chlorid bei der Zementerhaertung. ZementKalk-Gips 22, pp. 447-456, 1969.

[10] Arya, C., Buenfeld, N.R. and Newman, J.B., Factors influencing chloridebinding in concrete. Cement \& Concrete Research 20, pp. 291-300, 1990.

[11] Breit, W., Critical corrosion inducing chloride content - State of the art and new investigation results. Concrete Technology Report. VDZ., 2000.

[12] Concrete Society Technical Report No. 71: Concrete Petrography - An introduction guide for the non-specialist. Concrete Society, 2010. 